\title{
Another Phoenix VA Director Leaves
}

The Arizona Republic reports that the director at the Phoenix VA Medical Center, Deborah Amdur, will retire after only 9 months for health reasons (1). Amdur will be replaced by Barbara Fallen, director of the VA Loma Linda Healthcare System. Fallen will be interim director until a permanent replacement for Amdur can be found. This is the fifth hospital director since former Director Sharon Helman was removed in mid-2014 amid the nationwide veterans health-care scandal that was first exposed at the Phoenix VA.

The Veterans Integrated Service Network (VISN) in Gilbert, which oversees the VA Medical Center in Arizona, New Mexico and West Texas has also been through a series of 4 directors since Susan Bowers retired under pressure in the wake of the VA scandal. Marie Weldon, current acting regional director, also oversees the Los Angeles-based VA Desert Pacific Healthcare System. Weldon described Fallen as "an experienced leader who will continue the tremendous effort being made to improve access to high quality health care for veterans in the Phoenix area."

Amdur's retirement comes just one day after 12 News KPNX in Phoenix reported a taped conversation between a patient and employees at the Southeast VA Clinic in Gilbert (2). During the visit a nurse called the patient phone scheduling system "a nightmare", and a doctor employed by the VA for 3 months said he was "not a fan of the VA" and complained that assigning him 500 patients on May $23 r d$ did not allow him sufficient time with patients. According to the tape the doctor expresses his desire to help but simply states, "It's just I'm so lost in what to do." Regarding the audio recording, Director Amdur said before her resignation that "the agency is looking into the matter" and threatened "actions with the providers involved".

Congressman Matt Salmon, who represents Arizona's 5th District which includes the Southeast VA Clinic, told 12 News he was "disappointed" by what the audio recording revealed and does not consider it an anomaly. Salmon said while there are pressing matters facing the agency, he is optimistic new leadership can help turn it around. "I have nothing but praise for Director Amdur who is running the (Phoenix) VA. I think she is a breath of fresh air," Salmon said. "But the problem is so many people who still work there are the people that were there when the problem was created and getting rid of people that don't do the job the way they are supposed to is almost impossible in the VA." Salmon said the VA's HR system needs to be revamped in order to recruit higher-quality employees. "It needs to be streamlined so that when they find good doctors they are able to hire them quickly," Salmon said.

Amdur's threats and Salmon's comments are in line with the last 2 and a half years of VA excuses for poor care by blaming bad employees rather than mismanagement and lack of oversight. Both the nurse and the doctor are new to 
the VA and will likely shortly be gone for telling the truth further worsening the shortage of providers. As predicted 2 and half years ago, no fundamental changes have been made at the VA and it is not surprising that problems with patient scheduling persist (3). The last 20 years demonstrate that if the VA wants to provide the best of care, it is time to stop putting VA bureaucrats in charge and replace them with professionals who know something about it, doctors and nurses. Those doctors and nurses need to be overseen by a local committee of professionals to ensure that Veterans get the best of care. Otherwise no real change occurs and VA bureaucrats and politicians will continue to blame bad employees rather than a bad system. If no fundamental change is made, it may be time to scrap the VA system and send patients to outside providers as suggested by both the patient who made the recording and implied by Salmon.

Richard A. Robbins, MD*

Editor, SWJPCC

\section{References}

1. Wagner D. Phoenix VA hospital getting yet another boss. Arizona Republic. August 26, 2016. Available at: http://www.azcentral.com/story/news/local/phoenix/2016/08/26/phoenix-vahospital-getting-yet-another-boss/89412700/ (accessed 8/27/16).

2. Dana J. VA cancer patient secretly records doctor visit. 12 News KPNX. August 25, 2016. Available at: http://www.12news.com/news/local/valley/vacancer-patient-secretly-records-doctor-visit/307185216 (accessed 8/27/16).

3. Robbins RA. VA administrators breathe a sigh of relief. Southwest J Pulm Crit Care. 2014;8(6):336-9. doi: http://dx.doi.org/10.13175/swipcc077-14.

*The views expressed are those of the author and do not necessarily reflect the views of the Arizona, New Mexico, Colorado, or California Thoracic Societies or the Mayo Clinic. Dr. Robbins does see VA patients under the Veterans Choice Act. 